\title{
As experiências formativas da atriz Aracy Cortes e sua qualidade mulata: o teatro de revistas como espaço de práticas educativas difusas no Rio de Janeiro dos anos 1920
}

THE FORMATIVE EXPERIENCES OF THE ACTRESS ARACY CORTES AND ITS MULATA QUALITY: THE VAUDEVILLE AS A SPACE FOR DIFFUSED EDUCATIONAL PRACTICES IN RIO DE JANEIRO IN THE 1920s

https://orcid.org/0000-0002-0482-888x Rebeca Natacha de Oliveira Pinto ${ }^{\text {A }}$

${ }^{\text {A }}$ Secretaria de Estado de Educação do Rio de Janeiro (Seeduc RJ), Rio de Janeiro, RJ, Brasil

Recebido em: 29 abr. 2021 | Aceito em: 29 ag. 2021 Correspondência: Rebeca Natacha de Oliveira Pinto (rebecanatacha@gmail.com)

\section{Resumo}

A partir da trajetória de Zilda de Carvalho Espíndola (1905-1985), também conhecida como Aracy Côrtes, este trabalho se propõe a refletir sobre as desigualdades de gênero e raça na capital federal, nos anos 1920. Desta forma, suas origens, processos educativos e os espaços por onde atuou, nos permitem iluminar um caminho possível, e muitas vezes tortuoso, para a ascensão social através no universo do entretenimento. Na tentativa de articular cultura e educação, busco apreender através de suas experiências artísticas, especialmente a personagem "Mulata", um destaque na carreira dessa atriz e cantora, como os debates sobre nação, gênero e raça eram construídas nos palcos do Teatro de Revistas do Rio de Janeiro, no alvorecer do novecentos.

Palavras-Chave: gênero; Pós-Abolição; Rio de Janeiro; teatro.

\begin{abstract}
Based on the trajectory of Zilda de Carvalho Espíndola (1905-1985), also known as Aracy Côrtes, this work aims to reflect on gender and race inequalities in the federal capital, in the 1920s. Thus, its origins, educational processes and the spaces where she worked, allow us to illuminate a possible, and often tortuous, path to social ascension through the entertainment universe. In an attempt to articulate culture and education, I seek to apprehend through her artistic experiences, especially the character "Mulata", a highlight in the career of this actress and singer, as the debates about nation, gender and race were built on the stages of the Vaudeville of Rio de Janeiro, at the dawn of the nine hundred.
\end{abstract}

Keywords: gender; Post-Abolition; Rio de Janeiro; theater. 


\section{Introdução}

No presente trabalho, a trajetória Zilda de Carvalho Espindola (1904-1985), também conhecida como Aracy Côrtes, será explorada como um caminho para a compreensão da profunda relação entre a vida cultural, os conflitos raciais e as possibilidades de práticas educativas difusas na cidade do Rio de Janeiro na Primeira República. Nesse universo, esta pesquisa tem a perspectiva de ampliar os estudos sobre as possibilidades de práticas educativas femininas vivenciadas na capital federal, entre elas o teatro, no intuito de compreender como a educação foi um espaço de intensas negociações sociais nas primeiras décadas do século XX. Neste período, as representações sobre a construção da nação estavam sendo permeadas pelos embates sobre a ampliação da participação política feminina ${ }^{\mathrm{i}} \mathrm{e}$ as hierarquias raciais ${ }^{\mathrm{ii}}$, demandas colocadas pelos processos de emancipação dos escravos e pela composição multirracial e étnica da população (MATTOS, 2009, P.18).

Para este artigo, proponho pensar suas vivências de Zilda de Carvalho Espíndola no teatro de Revistas, limitando nossa temporalidade ao Rio de Janeiro da Primeira República. Nossos indícios para tal pesquisa serão os periódicos do referido período, peças teatrais, assim como a biografia de Aracy Cortes - Linda Flor. Desta forma, suas origens, processos educativos e suas principais personagens - a mulata e a baiana -, apontam para as possibilidades de ascensão social por meio do mundo do divertimento e lazer nas primeiras décadas do século XX. Este artigo se apresenta como fruto das minhas reflexões no doutorado, adentrando especialmente nas relações entre o teatro de revistas e as questões raciais que permeavam o cotidiano da cidade do Rio de Janeiro.

\section{Entre a rua do matoso e os palcos do teatro amador}

Destacada como uma das maiores vedetes dos palcos musicados, Aracy Côrtes teve uma longa carreira artística, como atriz, empresária e cantora do rádio, sendo aqui suas vivências nos palcos do teatro de revistas nos anos 1920 nosso principal objeto de análise. Isso se deve, especialmente, em função das escolhas de Aracy por se dedicar ao canto e a montagem de uma companhia teatral - a Companhia Aracy Cortes - no começo da década de 1930.

Nasceu no Rio de Janeiro, na capital federal, em 31 de março de 1904, filha de Argemira de Carvalho Espíndola e Carlos Espíndola ${ }^{\text {iii }}$. O casal possuía três filhos, além de Zilda, Silvino e Dalva, e residiram, durante alguns anos, na Rua do Matoso, próximo à Praça da Bandeira. Essa localidade estava situada próximo ao bairro de São Cristóvão, sendo um espaço muito 
utilizado para montagem de lonas circenses. Inúmeros circos construíram atividades fixas nessa região, como o Circo Spinelli e o Dudu Circo, entre outros. E será num destes espaços que a atriz Zilda Espíndola (ainda sem a alcunha de Aracy Côrtes) começará sua carreira profissional.

A família Espíndola, após a saída da Praça da Bandeira, se muda para o bairro do Catumbi, sendo vizinha de Alfredo da Rocha Vianna (Pixinguinha ${ }^{\text {iv }}$ ). Observa-se como a Zilda cresceu num ambiente em que o contato com as artes fazia parte do seu cotidiano. Ruiz aponta que a "menina cresceu numa modesta casa, [...] encravada num bairro onde havia tocatas noturnas pelas ruas e onde se formaria a primeira escola de samba, sendo ainda um reduto de ciganos" (1984, p.13-14). Dalva Espíndolav , irmã de Zilda, também construiu uma carreira artística, sendo atriz da Companhia Negra de Revistas, nos anos 1920 (BARROS, 2005). Desse modo, as experiências artísticas vividas pelas irmãs propiciaram alternativas para que as mesmas escolhessem trabalhar no universo do entretenimento carioca nas primeiras décadas do século XX.

Em entrevista, Zilda de Carvalho Espíndola afirma

Sou carioca. Nasci na Rua do Matoso, no dia 31 de março do ano da Graça de Nosso Senhor, o Samba. [...] Aos domingos sempre ia com a minha familia e amigos assistir as representações num Café Concérto que existia no Passeio Público. Garota ainda, estreei no Circo democrático, ao lado do saudoso Benjamim (Para Todos, em 07 de julho de 1924).

Em estudos sobre a trajetória de atores e atrizes, articulando seu processo formativo, Ângela de Castro Reis destaca que a que a família era "responsável pelo aprendizado artístico inicial". Para a autora, tais práticas vão se consolidando "no enfrentamento com o fazer teatral, ou seja, assimilando técnicas de atuação pela vivência das artes e não de um conjunto de conhecimentos formalizados a priori” (REIS, 2015, p.01). Assim, é possível apreender que, antes de experimentar ensinamentos em espaços educativos formais, Zilda já vinha adquirindo, em uma aproximação com o núcleo familiar - pai e irmã - habilidades importantes para a sua carreira artística.

Nessa perspectiva, o espaço doméstico se destacava como uma etapa inicial no estabelecimento de "[...] princípios morais, desenvolver, formar e instruir os sujeitos a partir dos conhecimentos acumulados pela humanidade, preparando-os para seus devidos papéis sociais" (VASCONCELOS, 2005, p.16). Para além dos conhecimentos aprendidos na escola, atividades educativas eram veiculadas em casa, através das artes e da imprensa carioca, objetivando à manutenção dos valores de mundo às novas gerações (ANJOS, 2015, p.55). 
As experiências narradas por Zilda de Carvalho Espíndola fornecem índicos para compreender tais proposições, visto que espaço doméstico e o ambiente cultural da cidade do Rio de Janeiro dialogaram intensamente na formação e desenvolvimento dessa importante artista do teatro de revista. No entanto, as vivências educacionais institucionalizadas são uma importante etapa na trajetória de Zilda de Carvalho Espíndola. Tendo sido destacada por ela em uma entrevista:

[...]Fui criada pela minha madrinha, uma senhora de alta sociedade, uma megera que me dava surras de meia-noite. Era uma criança marcada por beliscões. Mas o que ela me ensinou, aproveitei bem. Não completei curso nenhum, fui até o segundo ano ginasial [...]. Hoje tenho curso de inglês, de música e não me envergonho de minha gramática (BRASIL, 1977, p.19-20).

Zilda salienta os ensinamentos adquiridos no "ginasial", uma vez que desenvolveu seus estudos de gramática, tendo ainda aprendido inglês e música. Ao evidenciar que "não se envergonha da sua gramática" e que foi "até o segundo ano ginasial”, destaca ainda o papel importante que tais conhecimentos tiveram na sua trajetória. Gondra e Schueler afirmam que "a escola como dispositivo de educação e modo de socialização das crianças angariou adeptos ao longo do século XIX, o que se manifesta tanto no incremento das iniciativas públicas e privadas quanto no crescimento do número de matrículas, [...] especialmente de meninas" (2008, p.217).

A partir dessa entrevista fornecida por Zilda, podemos entender que diferentes experiências educativas eram possíveis a meninas e mulheres na Primeira República. Diversos estudos têm salientado a pluralidade de experiências educativas femininas em diferentes grupos sociais, desde o século XIX. Como apontei anteriormente, para além das instituições pedagógicas, a educação e as primeiras letras também costumavam ser transmitidas pelas mães, criadas e outras mulheres das famílias, ou ainda pela ação de preceptoras ou professores contratados. Para as meninas e mulheres das camadas mais abastadas, a formação englobava saberes relativos à administração doméstica, bem como a aquisição de normas de conduta e hábitos da cultura urbana, valorizando a música e as artes. Para as camadas populares, a escola primária, onde aprendiam trabalhos manuais de agulha e bordados, se constituía também como um meio de preparo para o exercício de ofícios remunerados, o que era fundamental para a sobrevivência de suas famílias (GONDRA \& SCHUELER, 2008, p.206).

A formação da artista tratada neste artigo nos possibilita perceber como os processos educativos vividos por muitas meninas e mulheres, e como estas construíram uma atuação social e participação política importante na capital federal, nas primeiras décadas do 
novecentos. Zilda de Carvalho Espíndola frequentou a escola primária, tendo cursado até o segundo ano do ensino secundário com a ajuda da madrinha. Esteve com o pai em muitas das apresentações musicais realizadas pelo mesmo e seus parceiros musicais, compartilhou experiências no Democrata Circo, próximo a sua primeira casa, com a direção de Benjamin de Oliveira $^{\text {vi }}$, tendo começado como cantora e atriz comercial neste referido circo (RUIZ, 1984, p.15).

Para além dessas experiências, antes de estar sob a tutela desse importante palhaço negro, Zilda frequentou o teatro amador, a Sociedade Dramática Filhos de Talma. Este foi um importante espaço de formação e adensamento das escolhas artísticas dessa artista. Nesse viés, cultura e as artes foram um importante espaço de aprendizado e trabalho feminino, seja como camareiras, atrizes, cantoras ou empresárias, entre outras. E nesse ambiente, Zilda conquistou um grande destaque no mundo artístico, sendo essa sua opção profissional, não restringindo seu horizonte e suas escolhas ao universo doméstico. De tal modo, estudar a trajetória de Zilda de Carvalho Espíndola permite a nossa percepção de como possibilidades estavam em disputa, compreendendo que entre o lar e os palcos das revistas cariocas havia uma infinidade de nuances tangíveis a muitas mulheres.

\section{A sociedade dramática filhos de talma e o teatro de revistas}

Em 1932, quando realiza uma entrevista à Para Todos, Zilda de Carvalho Espíndola afirma que suas primeiras apresentações teatrais se deram no teatro amador, quando possuía entre 15 e 16 anos (Para Todos, 07 de julho de 1932.p. 07). Mais especificamente, na Sociedade Dramática Particular Filhos de Talma. Esta instituição se localizava no bairro da Saúde, na Rua do Propósito, $n^{\circ} 12{ }^{\text {vii }}$ Foi inaugurada em 1879 e possuía um público bastante heterogêneo.

A presença de negociantes e operários na organização e liderança da Filhos de Talma, dialogava com a participação de muitos trabalhadores pobres, moradores das cercanias da agremiação. Essa composição multifacetada se devia também ao bairro onde estava situada a associação. A Saúde se estabelecia na zona portuária, visto que muitos de seus moradores trabalhavam no Porto, além dos inúmeros comércios que se estabeleciam no local (MOURA, 1995). No início do século XX, o bairro fazia parte da chamada "Pequena África", região da cidade que concentrava uma grande parcela da população mestiça e negra, sendo também próximo à residência de Zilda.

As associações amadoras de teatro eram muito mais do que grupos recreativos, culturais ou dramáticas. Essas organizações se constituíam também como ambientes de afirmação e 
exercício da cidadania. Auxílio mútuo, educação e lazer faziam parte do cotidiano das entidades amadoras, construindo redes de solidariedade e sociabilidades entre seus participantes (BATALHA, 2009, p.64). Por este motivo, saliento essas vivências formativas na trajetória de Zilda de Carvalho Espíndola, visto que, para além de suas experiências institucionalizadas (no ensino primário e o "colegial"), a artista pôde ampliar suas reflexões acerca das questões sociais, seja nos cursos que eram ministrados pela instituição, na sua participação no corpo cênico ou através das obras literárias que lia - visto que a associação possuía uma enorme biblioteca (ALMANACK DOS THEATROS, 1910, p.45).

Observa-se que não apenas a Filhos de Talma possuía notoriedade como instituição de teatro amador. No início do novecentos, vemos uma enorme quantidade de requisições para licenças de funcionamento, nos registros da polícia do distrito federal (GOMES, 2004, p.72). Penna Franca afirma que, entre 1865 e 1930, diferentes entidades amadoras, identificadas como grêmios, clubes, teatrinhos e sociedades amadoras constituíam-se como espaços de formação social, promovendo práticas de letramento, palestras diárias, encontros e debates de textos teatrais que permeavam o cotidiano da cidade (FRANCA, 2011, p.36). Muitos destes espaços possuíam sua própria sede - e nessas incluíam-se sala de teatro e biblioteca, bem como um espaço para encontros sociais e publicação de periódicos.

Percebe-se uma valorização da leitura, da oratória, da declamação em diferentes associações amadoras. Sílvia Cristina Martins de Souza destaca que mesmo com a presença de associados analfabetos, o texto teatral impresso era veiculado "em voz alta, vislumbrando um tipo de leitura denominada intensiva. Tais textos obedeciam a leis e regras próprias à transmissão oral e comunitária" (SOUZA, 2009).

As experiências de Zilda de Carvalho Espíndola no circo, nas companhias teatrais e, especificamente, no teatro amador salientam a importância de entendermos as práticas educativas para além da escola. Para Brandão, a educação é uma prática social construída a partir dos saberes existentes na diversidade cultural (BRANDÃO, 2005, p.11). Ou seja, experiências de aprendizagem são vivenciados em múltiplos setores da sociedade, seja em casa, na rua, igreja, espaços culturais e, também, na escola. Este autor afirma que, por toda parte, podem haver "redes e estruturas sociais de transferência de saber de uma geração a outra, onde não foi sequer criada a sombra de algum modelo formal e centralizado" (BRANDÃO, 2005, p.13).

Monica Pimenta Velloso salienta o impacto comunicativo das encenações circenses e teatrais, alcançando parte da população analfabeta ou semi-escolarizada, e possibilitando-lhe 
construir outros canais de diálogo com o código letrado e as questões sociais latentes na Primeira República (VELLOSO, 2000, p.238). Thompson afirma que essa circularidade dos saberes cumpria um papel fundamental no desenvolvimento da consciência da classe operária, uma vez que permitia o acesso dos mais pobres aos domínios culturais privilegiados de grupos dominantes (THOMPSON, 1989, p.238). Para esse autor, a maior parte dos elementos que constituiriam uma cultura intelectual rigorosa e vigorosa viria do uso do tempo livre, não apenas por meio das práticas de entretenimento, mas também desfrutando momentos que permitissem a fruição e a "exploração aberta do mundo" população (BERTUCCI, FARIA FILHO \& OLIVEIRA, 2010, p.76). O código letrado e a oralidade intercambiavam-se no cotidiano dos diferentes clubes e grêmios dramáticos, isso porque cursos de primeiras letras, canto, dança e da arte de representar eram ministrados com o objetivo de desenvolver e edificar os talentos dos integrantes dessas sociedades.

A partir da trajetória de Zilda de Carvalho Espíndola tracejam-se alguns dos processos educativos difusos na cidade do Rio de Janeiro, nas primeiras décadas do novecentos. Não apenas suas oportunidades em espaços institucionalizados permitiram seu acesso e ampliação ao código letrado, mas também suas vivências na Sociedade Dramática Particular Filhos de Talma e no Democrata Circo. Tais experiências nos permitiram vislumbrar inúmeras possibilidades formativas e de participação social para meninas e mulheres, em meio às profundas desigualdades de gênero e raça na capital federal.

\section{Entre a mulata e a baiana: as principais personagens de aracy côrtes}

Depois de experiências no Teatro amador, e uma breve passagem pelos palcos circenses, Zilda de Carvalho Espíndola ancorou-se nos palcos comerciais do teatro de revistas. Logo nas suas primeiras apresentações, ganha o nome artístico de Aracy Cortes, e passa a ser destaque em diferentes companhias teatrais na cidade do Rio de Janeiro nos anos 1920. Contudo, neste artigo, nos debruçaremos sobre suas duas personagens de maior destaque: Mulata e Baiana.

A especialização dos atores era uma das peculiaridades do teatro de revista na Primeira República. Reis afirma que "cada companhia possuía um naipe de atores que, a partir de características físicas e psicológicas, especializavam-se em determinados papéis” (REIS, 1999). Nos anos 1920, composições revisteiras traziam a constante presença de três personagens-tipo: o português, a mulata e o malandro (CHIARADIA, 2012, p.156). Esses propiciavam aos autores enredos recheados de conflitos e comicidade, dialogando com o que acreditavam ser representativamente nacional (AGUIAR, 2013, p.74). 
O samba maxixado Graça de Aracy, de Ary Barroso, composição para a peça Não Adianta Chorar, lançada em 1929, e estrelada por Aracy Côrtes, fornece indícios para perceber alguns dos adjetivos atribuídos à essa atriz, cantora e empresária nos palcos musicados:

Tem uma graça feiticeira,
Só porque aqui nasci
Nesta terra brasileira
Com meu cheiro de canela
Minha cor de sapoti
Dizem todos: Lá vem ela!
O demônio da Araci! ${ }^{\text {viii }}$

Entre as denominações de Ary Barroso, ressaltam-se "o cheiro de canela", "cor de sapoti", vinculando a artista a características negras, percebendo também como as desigualdades de raça, gênero e classe se intercambiavam nas revistas cariocas dos anos 1920 . Analisei diferentes peças teatrais encenadas por Aracy Côrtes ao longo da década de 1920, dedicando uma maior atenção à Não adianta Chorar, La Garçonne e Miss Brasil, e, em todas as vezes em que tais personagens estiveram em cena, foram representados por Aracy. Ou seja, suas encenações mais expressivas estavam associadas à população negra e mestiça.

Quando cotejei a possibilidade de estudar a Zilda de Carvalho Espíndola - a Aracy Côrtes -, acreditei, pelos anúncios nos jornais, pelas caricaturas e por ter como personagens de destaque a baiana e a mulata que a mesma fosse uma atriz negra de sucesso nos palcos do Teatro de Revistas. Ao me debruçar sobre os periódicos e as fotografias publicadas no livro Linda Flor, de Roberto Ruiz, percebi que, por mais que Aracy fosse referenciada pela sua "cor de sapoti”, a sua qualidade mulata não estava atrelada apenas à tonalidade de sua pele, mas aos elementos que compunha em cena. A mesma possuía um tom de pele pouco pigmentado, entretanto tinha um tipo de corpo, mais avantajado, que era comumente associado a personagem mulata. Reconhecida como cantora de sambas e maxixes (sendo responsável pelas apresentações desses gêneros musicais nas composições revisteiras), tendo uma pele pigmentada em associação à fruta "sapoti", a mesma foi construindo uma identificação com os elementos de matriz africana (LOPES, 2008, p.88).

Na peça Miss Brasil, em que Aracy representa a Mulata, as personagens Brasílio e Cabral afirmavam a importância da mesma para a cidade do Rio de Janeiro. No quadro intitulado "Independência ou Morte”, Brasílio e Patrício advertem Agache:

AGACHE (desembrulhando os canudos sobre a mesa, com estouvamento, afastando todo mundo)

Mes amis! O Rio de Janeiro quelle merveille! ... Ici... $[\ldots]$ 


\section{AGACHE}

C'est une question d' estethique...

CABRAL

È, mas com tua esthetica pra cá vens de carrinho...

[...]

MULATA ( a Brasílio)

Chi, meu nêgo! Quem é esse corpo estranho?

BRASÍLIO

È o professor Agache, Mulata! O urbanista que vem acabar de botar os morros abaixo!

MULATA (a Agache)

Ah, mussiù! O senhô é urbanista?

AGACHE (passando à mão no queixo da mulata)

Non, mulate....Je suis.... cubiste..

[...]

CABRAL

É a voz do sangue! Escangalha-me a cidade, passa-me a Avenida Central pra rua Pinto de Azevedo; mas não me estragues a raça da mulata! A única coisa que eu ainda conservo como certa! Conserva, seu Agache! O Rio se agacha, mas a mulata, nunca! Enquanto houver um português bradando às armas, defenderei a mulata! (Protegendo a mulata solene) Independência ou morte!

(Dá dois tiros para o ar). ${ }^{\text {ix }}$

A peça Miss Brasil, escrita e encenada em 1928, estava dividida em dois atos e abordava, em conversa entre as personagens, as críticas acerca das propostas de mudança na capital federal idealizadas pelo estudioso francês. Alfred Agache havia realizado uma viagem ao Brasil, em 1927, projetando alterações na arquitetura das cidades do Rio de Janeiro, Curitiba, entre outras (MENDES, 2012).

Trazendo à tona o viés da sensualidade, para além da tipificação erotizada das mulheres afro-brasileiras, a peça Miss Brasil propõe à mulata o papel da nacionalidade. Tal questão é ainda mais ressaltada quando Marques Porto e Luís Peixoto, autores da composição teatral, descrevem que a personagem está "trajada com fitas de verde e amarelo", as principais cores da bandeira nacional. A mulata é retratada como um elemento de nossa cultura que não poderia ser alterado, diante de tantas interferências externas, urbanísticas ou não, sendo necessária a união entre brasileiros e portugueses para defendê-la.

Lilia Schwartz auxilia no entendimento de tais questões ao afirmar que, em diferentes canções populares, a associação da mulata à identidade nacional brasileira era recorrente (2012). Construindo suas análises sobre sambas da década de 1930, os argumentos da autora também são válidos para as primeiras décadas do século XX, uma vez que, desde o advento da República, havia um esforço coletivo na produção de uma imagem positiva do país. Para tanto, a mistura das raças e o ideal da mestiçagem - entre brancos e negros, visto que a cabocla índia pouco aparece em canções no pós-abolição - foram se consolidando como lócus da 
autenticidade nacional, sendo a mulata a maior representação de tais proposições (ABREU, 2004; BRAGA, 2003; CORRÊA, 1996; LOPES, 2009; PEREIRA, 2010; LANZARINI, 2014). Longe de querer dedilhar sobre o mito da democracia racial em nosso país (ORTIZ, 1986; GUIMARÃES， 2002; AZEVEDO， 1987; SCHWARCZ，1996; SUSSEKIND， 1982; MUNANGA, 2009; PEREIRA, 2013), esse estudo se faz na tentativa de perceber como a personagem mulata foi acionada pelos revistógrafos cariocas para, pedagogicamente, consolidar a imagem de um "equilíbrio entre as raças".

O teatro possibilitava instruir e propagar normas, valores e cultura. Viabilizava a construção de novos espaços de circularidade e de sociabilidade das letras, aproximando, profundamente, oralidade e escrita (DAVIS, 1990, p.159). Por meio das representações produzidas nessas composições teatrais, podemos apreender como o teatro foi um campo para as disputas em torno dos significados acerca da identidade nacional. ${ }^{\mathrm{x}}$

E é nesse sentido que busco estudar o teatro de revistas, ponderando a sua dimensão pedagógica, intrinsecamente imbricada à formação dos sujeitos e à vida social e cultural carioca (SÁ, 2009). Nesta perspectiva, procuro evidenciar como práticas educativas difusas se conjugavam à escolarização, fornecendo oportunidades de debate e participação social vinculada ao ambiente cultural da cidade. As experiências de Aracy Côrtes na cena teatral, nos permite dialogar com o profundo racismo e sexismo que permeavam os debates acerca da formação da identidade nacional. Através da ironia e da comédia, as composições do teatro de revista, ao trazerem a personagem mulata, incorporavam a valorização da presença da cor, transformando-a em motivo de orgulho para a população. Buscava-se, assim, atenuar o racismo presente na sociedade brasileira. Entretanto, escamoteava das percepções sobre nacionalidade a população negra mais pigmentada. Para Schwarcz,

O corolário dessa façanha é a elaboração de uma certa resposta, digamos assim, capaz de organizar o passado nacional, fazer inteligível seu presente e explicar, diante das outras nações, o que nos tornaria diferentes. [...] A cor está presente, mas é quase um cenário que resguarda as diferenças [...]. Isso sem falar da figura da mulata, que, exportada em virtude de sua beleza exótica e sensual, convertia-se cada vez mais num ícone de uma certa brasilidade. De toda a forma, nesse movimento de nacionalização, uma série de símbolos vão virando mestiços, assim como uma alentada convivência cultural miscigenada se torna modelo de igualdade racial (2012, p.66).

Canções, peças teatrais, periódicos e produções literárias ajudavam a formar os ideais miscigenados na sociedade brasileira, na tentativa de mitigar as hierarquizações raciais, presentes no cotidiano carioca da Primeira República. Antônio Herculano Lopes complexifica tais questões, ao salientar que, desde o período imperial, nos palcos cariocas, a negritude foi marcada pela presença de artistas mestiços, limitando "traços da cultura negra na formação de 
uma arte nacional" (2009, p.86). Ou seja, mulatos faziam parte do quadro profissional de companhias cariocas, como atores, atrizes, cantoras ou músicos, alcançando notoriedade e construindo personagens ligados à questão racial (ABREU; MARZANO, 2009).

Torna-se importante trazer à tona a diferenciação da personagem-tipo para o estereótipo. Para Taveira, esse último apresenta características estampadas e traços comportamentais evidentes, o que limita as ações das personagens (2009, p.08). Já a personagem-tipo opera numa síntese de características, que implica a identificação a um grupo pessoas, e possibilita às personagens agirem de diversas formas, não apenas aquelas esperadas pelo público (TAVIEIRA, 2009, p.09).

No tocante à mulata, percebe-se como essas qualificações são mescladas, visto que os revistógrafos e a imprensa carioca, muitas vezes, se aproveitavam da construção de personagens, para promover estereótipos sobre a população negra e mestiça. E isso pode ser observado na charge a seguir, produzida para representar a "qualidade mulata" de Aracy:

FIGURA 1 - Aracy Côrtes, desenho de Alceu Pena, em 1928

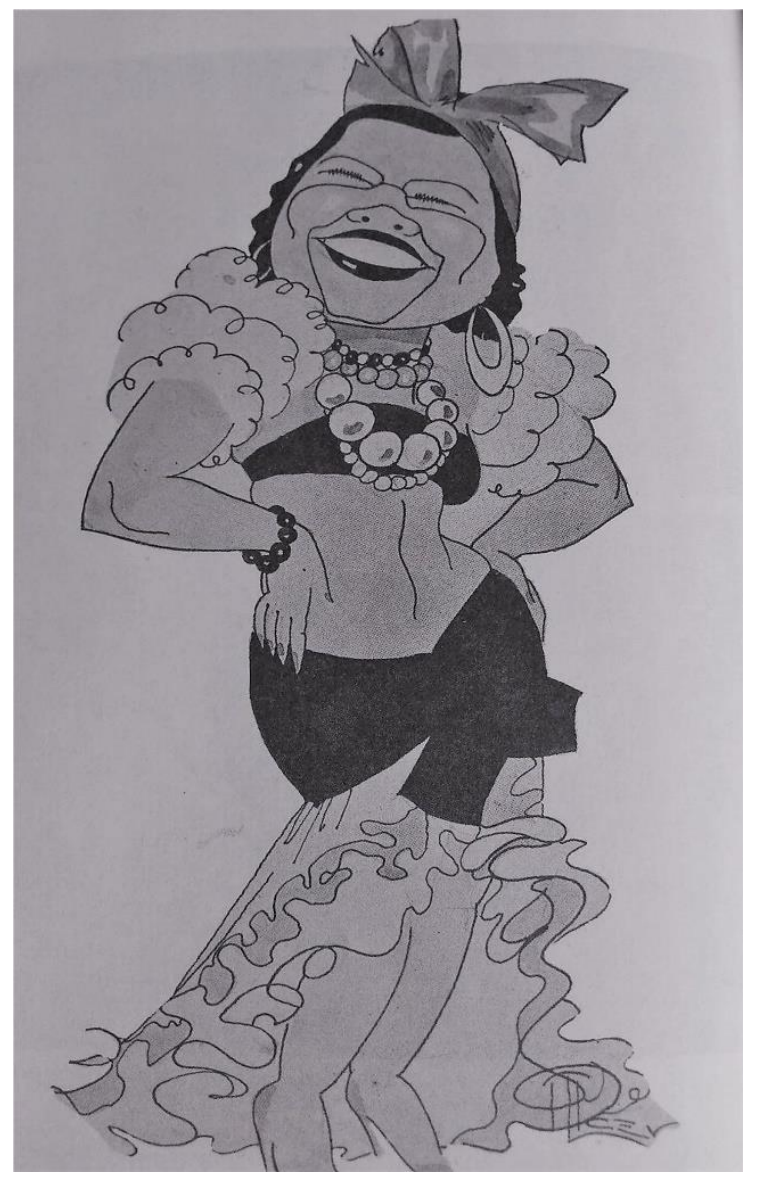

Fonte: RUIZ, 1984. p. 163. 
Para Monica Pimenta Velloso, a caricatura vinculava-se à modernidade, uma maneira de narrar, de forma teatralizada, acontecimentos do cotidiano (1996, p.63). Para Abreu, "através do cômico, do irônico, do risível, do ridículo e do deformado os artistas imprimiam sentidos à realidade e ao que era representado" (ABREU, 2017). Com todo o seu potencial pedagógico, as caricaturas auxiliavam na difusão de uma interpretação dos afrodescendentes com sinais "animalizados e aceitos pela sociedade como racialmente inferiores" (ABREU, 2017).

Desenhada por Alceu Pena, em 1928, com características fenotípicas compreendidas como pertencentes às mulheres negras - quadris largos, nariz e boca expandidos -, Mario Nunes destaca que Aracy era percebida como "uma artista mestiça típica dos gêneros nacionais" (NUNES, p.1956, p.46). Giovana Xavier afirma que tais charges ajudam a generalizar o rótulo científico da inferioridade particular das africanas e a difundir uma percepção das mulheres negras enquanto objeto exótico, que necessitavam estar "à intervenção, à subordinação e ao controle irrestritos" dos homens (2012, p.110). Angela Davis auxilia a compreensão desses estereótipos, ao afirmar que racismo e sexismo se somam ao corpo das mulheres negras. Articulando a herança escravocrata e o profundo racismo nos EUA, no final do século XIX, a autora aponta que esse olhar objetificado engloba formas de violência, que são evidenciados em discursos que, com frequência, essencializam as mulheres negras como sensuais e promíscuas (DAVIS, 2016, p.181).

No Rio de Janeiro dos anos 1920, a denominação "mulata", possivelmente, seria atribuída à uma mulher na qual se reconhece algum grau de mistura racial. Nos palcos musicados, um fator determinante para que esse termo fosse aplicado era sua linguagem corporal. "É possível dizer que uma mulata era caracterizada por ter algum grau de ascendência africana visível em sua aparência, mas também deveria ser marcada por uma performance que sugerisse uma sexualidade marcante aos observadores" (GOMES, 2004, p.255).

Interessante perceber como a definição da "mulata" não estava fundada apenas no tom de pele. Gomes afirma que, para ser uma mulata dos palcos revisteiros, deveria possuir uma capacidade para o ritmo do samba, ser sexualmente atrativa - particularmente com uma concepção de corpo "violão", com cintura fina e pernas e nádegas avantajadas -, e ser "bem brasileira" (2004, p.255). Dessa forma, "a mulata se apresentava como um lugar privilegiado da miscigenação, mas sua ligação devia-se também à performance corporal e seu papel como símbolo nacional" (GOMES, 2004, p.255). 
Contribuindo, ainda mais, para o enriquecimento do debate sobre educação, gênero e raça nos palcos musicados da capital federal, observa-se como a escolha para a representação das personagens negras se fazia por Aracy Côrtes. Ou seja, uma "artista mestiça" acabava ocupando espaços de centralidade em detrimento de artistas negras mais pigmentadas. Fruto do racismo, tais escolhas revelam como as heranças das relações escravocratas permeavam as relações sociais no pós-abolição, e dialogavam com as teorias de branqueamento na população brasileira.

A peça La Garçonne adensa o debate, estrelada por Aracy Côrtes, tais questões podem ser observadas, especialmente, no diálogo entre as personagens Remígio e Firmino:

\section{REMÍGIO}

Aqui pra nós que ninguém nos ouve, eu ando enfeitiçado por uma mulata... ah, seu Firmino, que mulata!

FIRMINO (batendo-lhe na barriga)

Uma mulatinha café com leite, claro, hein seu Remígio?

REMÍGIO

Café com leite uma ova. Eu ando embuçado mas é por um cafezinho simples.

Cá comigo não há misturas.

[...]

FIRMINO

Mas escuta, Remígio: você não tem vergonha de andar com uma crioula na rua? Você, um rapaz bonito, elegante, chic?

REMÍGIO

Vergonha de que? Vergonha é roubar e não poder carregar. Uma mulata jeitosa, com cabeça a la garçonne de botequim e com um pouquinho de pó de arroz pra ficar cinzenta... ah, seu Firmino, até Jesus Cristo tem inveja.

$[\ldots]$

FIRMINO

Que isso?! No Brasil há tanta coisinha boa... tanta mulher bonita...

REMÍGIO

... mas tira-lhe a mulata e veja o que é que fica. Nada. ${ }^{\mathrm{x}}$

Apreende-se como a personagem Firmino, ao evidenciar "uma mulatinha café com leite" ajuda a enaltecer "a mestiçagem como instrumento de assimilação racial dos considerados grupos inferiores, de forma que escapavam da armadilha determinista que condenaria o Brasil ao atraso e à barbárie" (DANTAS, 2009, p.60). Dessa forma, as falas reverberam as teorias eugênicas, em voga no período.

Desde o fim do século XIX, ainda no Império, mas, fundamentalmente, com o fim da escravidão e com o advento da República (respectivamente 1888 e 1889), as discussões sobre a construção da "nação brasileira" giravam em torno da questão racial (DANTAS, 2009). Era necessário construir uma identidade nacional. Entretanto, tendo em vista a enorme influência 
das teorias raciais do século XIX, como construir uma identidade nacional - naquele momento ligada, diretamente, à ideia de raça que se constituía - com uma população cuja maioria descendia de ex-escravizados de origem africana e indígenas considerados, cientificamente, como inferiores?

A escolha da mulata, uma personagem que abarca a miscigenação com a população branca, sendo caracterizada pelo "café com leite", se apresentou como uma representação possível em "um processo de desafricanização de vários elementos culturais, simbolicamente clareados" (SCHWARTZ, 2012, p.58). Giovana Xavier, estudando a imprensa negra norteamericana nas últimas décadas do século XX, auxilia na percepção de tais questões em uma arena transnacional:

[...] o leitor percebe um processo de racialização próprio dos Negroes, que, através de experiências e percepções diferenciadas acerca da cor, construíram uma noção racializada de beleza assinalada por uma aparência feminina mulata (visualmente branca), jovem, urbana e moderna. Embora tenhamos usado o exemplo The Colored American Magazine, esse boom de pessoas mulatas não foi uma marca específica do magazine. Isto era uma verdadeira febre na imprensa negra do período, especialmente no caso feminino [...] $(2012$, p.89).

Para a autora, ao trazer à tona as hierarquias coloristas, simbolizadas por meio do contraponto imagético de black e mulato, os periódicos colaboraram na construção de uma definição de boa aparência que se vinculava à pele clara (XAVIER, 2013, 432). Apesar de adequada às exigências da modernidade - cosmopolitismo, urbanização, bom gosto, sofisticação - Xavier afirma que tais concepções foram gestadas historicamente, "nos tempos da escravidão, quando a epiderme clara foi se tornando um distintivo intrarracial primordial" (2013, 435).

Segundo Amílcar Araújo Pereira, nesse "grande debate", prevaleceram ideias de estudiosos do campo das ciências sociais e humanas que usaram e abusaram da metáfora darwinista da "sobrevivência dos mais aptos" e da eugenia ${ }^{x i i}$ para sugerir políticas públicas que promovessem, entre outras coisas, o branqueamento da população brasileira (PEREIRA, 2013, p.63). Diferentes intelectuais dialogaram com as ideias de Francis Galton ${ }^{\text {xiii }}$, responsável por cunhar o termo eugenia, em 1883; entre eles estavam João Batista de Lacerda (1846-1915), Sylvio Romero (1851-1914), Oliveira Vianna (1883-1951) e Raimundo Nina Rodrigues (18621906). Para Pereira, esses pensadores se articulavam, diretamente, com as teorias raciais vigentes em sua época, no Brasil e no exterior, e idealizaram uma saída original para a problemática racial brasileira - a Teoria do Branqueamento (2013, p.69). Através da miscigenação, por meio do grande fluxo migratório, vindo da Europa - incentivado pelos 
governos brasileiros de então -, teríamos o melhoramento da nação (PEREIRA, 2013, p.71). Essa teoria ganhou muita força no início do século XX, contribuindo para o debate entre intelectuais e homens da ciência, no Brasil, envolvendo médicos, educadores e juristas (MULLER, 2014, p.70).

Karoline Carula aponta que, desde o último quartel do século XIX, o pensamento eugenista circulava entre intelectuais e políticos da sociedade brasileira (2016, p.91). Pedagogicamente, através da construção de cursos e conferências públicas, assim como romances, músicas e espetáculos teatrais, buscavam racializar os debates acerca de uma nação adequada aos projetos civilizatórios.

Carolina Mafra de Sá salienta como o teatro se construiu como espaço de diferentes tensões e diálogos (SÁ, 2010). Analisando os jornais publicados em Ouro Preto e documentos oficiais mantidos pelo Arquivo Público Mineiro, a autora percebeu que, o teatro, desde meados do século XIX, foi considerado pelos dirigentes imperiais, e pelos próprios artistas e intelectuais, uma arte configurada para se constituir em "escola do povo". Mais que um "divertimento útil", o teatro simbolizava ilustração e civilidade, para além das divergentes posições sobre os seus significados sociais e culturais. (SÁ, 2010). ${ }^{\text {xiv }}$

$\mathrm{Na}$ virada do século XIX para o XX, atores e atrizes começaram a ganhar prestígio na sociedade, e passaram a ser vistos como responsáveis por uma importante tarefa: a de disseminar a civilização, a moral e os valores sociais diluídos na (e para) sociedade. (SÁ, 2010). Muitos literatos e intelectuais entendiam o teatro como uma "escola de costumes", ou seja, um local adequado para instruir e possibilitar a difusão de normas, valores e cultura (SOUZA, 2009). O teatro viabilizava também a maior difusão do código letrado, construindo espaços para debates em voga no cenário político-social, para novas sociabilidades, aproximando práticas e experiências culturais de oralidade e escrita.

E é nesse sentido que estamos compreendendo o diálogo da personagem Remígio, na peça La Garçonne. Nesta, afirma encantar-se por "uma mulata jeitosa, com cabeça a la garçonne de botequim e com um pouquinho de pó de arroz pra ficar cinzenta". Ou seja, os diálogos nas peças permitem a compreensão da circularidade entre as ideias científicas, em voga na Primeira República, e o universo do entretenimento carioca. E nos permitem compreender como as personagens mulata e a baiana se constroem como indícios das inúmeras opressões vivenciadas pelas mulheres negras no pós-abolição; evidenciando que, para além das desigualdades de gênero, adensava-se o complexo processo de racialização - produção de hierarquias e lugares sociais através da raça (MATTOS, 2005, p.14). 
Interessante analisar que a primeira trupe teatral de que Aracy Côrtes participou, a Companhia Arruda, era percebida por periódicos como $O$ Malho como uma companhia que buscava trazer, para as suas apresentações, elementos que se vinculassem a uma identidade negra. Esse referido periódico, exteriorizando preconceitos, aproximava os artistas da Companhia Arruda à macacos:

\begin{abstract}
Em certo dia da semana passada, um trem da Central, ou um navio do Lloyd, não se sabe bem, despejou, no Rio, um troço numeroso de caipiras, que logo ao desembarcar chamou a atenção de todo o mundo. (...) Deparando-se com o bando (...) e arreliado já por haverem trazido tanta costureira, tanto alfaiate, tanto pessoal do movimento (...) o René (...) mandou encostar o caminhão de reclames da empresa (...) e ordenou, já sem cerimônias: -Entra, negrada! (...) O chofer do caminhão-reclame passeou a macacada pela cidade, exibindo-a ao povo que lia em letras garrafais de cada lado do auto: Companhia Arruda - alguns dos curiosos espécimes da coleção (Malho, 23 de julho de 1921. p.08).
\end{abstract}

Trazer à tona esses discursos, associados às análises de peças teatrais, se faz na possibilidade compreender as ambiguidades que permeavam o universo do entretenimento. As concepções que ressaltavam a inferioridade da população negra se articulavam, numa mesma peça teatral, com o protagonismo de personagens mulatas nos palcos cariocas. Tais contradições faziam parte das relações sociais e complexificam a análise das fontes do teatro de revista. Com um caráter extremamente polissêmico, numa mesma cena, a afirmação da negritude com o personagem Remígio - que afirmava estar enfeitiçado por uma mulher negra, um "cafezinho simples" - dialoga com as ideias eugênicas de Firmino, que o questiona os desejos sobre uma relação com uma mulher negra mais pigmentada. Em meio a todo racismo, as desigualdades de gênero se somavam, construindo sobre as personagens negras percepções acerca da hiperssexualização e atribuição de juízo moral junto aos seus comportamentos sociais (SOUZA, 2017, p.11).

A personagem Remígio, ao perguntar se Firmino não teria "vergonha de andar com uma crioula na rua", propõe uma classificação entre as atitudes consideradas "elegantes, chics" e as manifestações "negras", apontando, também, para a ridicularização dessa última. Não apenas nas peças do teatro de revistas, mas nos diferentes periódicos da capital, apreende-se essas questões, nos quais não deveriam ser enaltecidos elementos encontrados em populações "mergulhadas na barbárie" (O eterno feminino. Careta, 29 de novembro de 1924. p.29). A revista Careta evidenciava que "as negras moças ou velhas da tribo dos Massais da África Central enfeitam-se tanto com bugigangas, brincos e pulseiras e pendéntifs como as nossas elegantes que passam pela Avenida Central" (Careta, 29 de novembro de 1924. p.29). Ou seja, as referências à África constroem-se na oposição entre barbárie e civilização. Categoricamente, 
à África eram atribuídos valores e características considerados inferiores, que não poderiam ser associados à Avenida Central - considerada o símbolo das elites e da "vida moderna" carioca.

É importante ressaltar que as composições teatrais eram textos humorísticos e não reais projeções sociais. Muito embora se apresentassem como poderosas lentes de aumento das questões sociais, realçavam o assunto que se desejava tematizar (GOMES, 2004, p.237). Afirma-se como, através da pilhéria e do riso, eram trazidos à tona o profundo racismo presente numa sociedade que tinha vivenciado a escravidão há poucas décadas. Em muitas canções e textos cênicos, hierarquias sociais estavam sendo representadas, nas quais a exploração e a submissão do corpo das mulheres afrodescendentes ao homem branco eram referendadas. Abreu salienta como o universo das artes foi um espaço muito utilizado para que identidades não brancas pudessem ser veiculadas, edificadas e reconstruídas (2004, p.155).

Se, por um lado, canções e peças teatrais divulgavam versos em que a mulata era vista como uma das nossas melhores marcas (neste sentido, poder-se-ia alegar que mantinham o sentido de objeto sexual atribuído às mulheres afrodescendentes, embora de uma forma não grosseira), por outro, os versos descrevem mulatas com um papel ativo - pouco condizente com a imagem de "coisa" ou objeto sexual - ora exercendo o seu poder de sedução, ora apoderando-se do dinheiro de seus "ioiôs", ora os dispensando (TAVIEIRA, 2009, p.15). Apreende-se como outras representações também eram possíveis. Especialmente no tocante à sua capacidade de envolver e conquistar os homens, tornando-os prisioneiros e dominados. Não obstante, encontra-se, também, registros de uma percepção como musa (certamente mais sexual que sentimental) dos corações masculinos, que parecia ganhar prestígio frente a outras imagens idealizadas da beleza feminina (TAVIEIRA, 2009, p.16).

Assim, para além da coisificação, nas peças de teatro de revista, a mulata vai ganhando outras possibilidades, entre elas, a de uma "mulher poderosa e autônoma que seduz quem deseja por interesses próprios" (AGUIAR, 2013, p.90). Antônio Sergio Alfredo Guimarães afirma que essas influências dialogavam com novas perspectivas acerca do negro, que estavam em circulação no alvorecer do século XIX e começo do século XX. O autor chama a atenção para a modernidade negra, ou seja, o processo de inclusão cultural e simbólica dos negros à sociedade ocidental no final do oitocentos. Ao lado da representação negativa do negro pelo branco, no início do século XX, faz-se, também, sua representação positiva, principalmente no universo da cultura e das artes, que se difundia pelas Américas, África e Europa (GUIMARÃES, 2004). 


\section{Considerações finais}

Aracy Côrtes me permitiu expandir as percepções acerca das possibilidades femininas na sociedade carioca nas primeiras décadas do século XX. Não tendo sido estudada enquanto um objeto isolado, trouxe à tona diferentes experiências vividas por artistas negras e mestiças. Entre elas sua própria irmã, Dalva Espíndola, para além de Rosa Negra, Deo Costa, entre outras. Em meio a toda ambiguidade que dialogava com as performances, racismo e protagonismo social foram vivenciados intensamente no ambiente cultural da capital federal.

As personagens encenadas por Aracy, suas imagens e os relatos na imprensa que a qualificavam como "tipicamente mestiça" ressaltam as profundas contradições que permeavam tais relações. Essa artista não apenas se construiu frente às dificuldades de classe, junto a uma família de poucas posses, residente da Pequena África, como ainda teve de se contrapor ao estereótipo de uma "humanidade menor", frente às desigualdades de gênero e raça, sendo essa última um potencializador de tais questões. Em meio a estas ambiguidades, articulou conquistas, dialogando com os estereótipos construídos acerca do corpo das mulheres negras, alargando suas oportunidades de protagonismo social no universo do entretenimento.

Busquei construir minhas análises para além das proposições realizadas por Maria Lucia Muller, que em seus estudos possibilita uma apreensão dos negros como "outsiders em sua própria sociedade" (MULLER, 2014, p.77). Articulando com as profundas ambiguidades presentes na capital federal no pós-abolição, percebe-se como protagonismos negros foram possíveis no Rio de Janeiro no alvorecer do novecentos. Mulheres e homens empreenderam diferentes estratégias de participação social e ampliação da cidadania, sendo necessário um olhar mais apurado para multiplicidade das fontes. Este estudo visa contribuir com essas questões, salientando ainda como o ambiente cultural foi um campo amplamente disputado para construção de práticas educativas difusas e para a repercussão de demandas e críticas à uma sociedade profundamente excludente. Construir um olhar de excepcionalidade, ou de raridade, para a ascensão social de mulheres negras na Primeira República seria um equívoco (XAVIER, 2013; XAVIER, 2016; HOOKS, 1995; ABREU, 2017).

Apreende-se como as mulheres negras, dos mais diferentes grupos sociais, buscaram articular política, arte e cultura, fazendo do universo do entretenimento um dos espaços de formação, erguendo e reelaborando novas possibilidades educacionais, na tentativa de ampliar seus direitos sociais. Em meio ao racismo e as desigualdades de gênero, dialogavam com a construção de uma identidade nacional, e almejaram construir para si estratégias e alternativas para a ampliação da participação feminina nos espaços públicos. 


\section{Referências}

ABREU, M.; Marzano, A. Entre palcos e músicas: caminhos de cidadania no início da República. In: Carvalho, J. M. de; Neves, L. M. B. P. (orgs.). Repensando o Brasil do oitocentos: cidadania, política e liberdade. 2009.

ABREU, M. Da senzala ao palco: canções escravas e racismo nas Américas (1870-1930). 2017. E-book.

Sobre Mulatas Orgulhosas e Crioulos Atrevidos: conflitos raciais, gênero e nação nas canções populares (Sudeste do Brasil, 1890-1920). Tempo. v. 8, n. 16. 2004.

AGUIAR, M. de A. O teatro de revista carioca e a construção da identidade nacional: $\mathrm{O}$ popular e o moderno na década de 1920. 2013. Dissertação (Mestrado em História). Programa de Pós-Graduação em História, Universidade do Rio de Janeiro.

ALMANACK dos Theatros. Publicação Ilustrada de Alvarenga Fonseca. Typ. Villas-Boas \& C., 1910.

ANJOS, J. J. T. A educação da criança pela família no século XIX: da historiografia a um problema de pesquisa. Rev. bras. hist. educ. v. 15, n. 1 (37), p. 51-81. jan./abr. 2015.

AZEVEDO, C. Onda Negra, Medo Branco: O Negro no Imaginário das Elites. 1987.

BARROS, O. Corações de Chocolat: A história da Companhia Negra de Revistas (1926-27). 2005.

BATALHA, C. H. M. A geografia associativa: associações operárias, protesto e espaço urbano no Rio de Janeiro da Primeira República. In: Azevedo, Elciene et al (org.).

Trabalhadores na cidade: cotidiano e cultura no Rio de Janeiro e em São Paulo - séculos XIX e XX. 2009.

BERTUCCI, L. M., Faria Filho, L. M. \& Oliveira, M. A. T. Edward P. Thompson: história e formação. 2010.

BRAGA, C. Em busca da brasilidade: teatro brasileiro na primeira república. 2003.

BRANDÃO, C. H. O que é Educação. 2005.

BRASIL. Depoimentos, v.III, 1977.

CABRAL, S. Pixinguinha: vida e obra. 2007.

CARULA, K. Darwinismo, raça e gênero: Projetos modernizadores da nação em conferências e cursos públicos (Rio de Janeiro, 1870-1889). 1ª ed., 2016.

CHARTIER, R. Pierre Bourdieu e a história - debate com José Sérgio Leite Lopes. Palestra proferida na UFRJ. 30 abr. 2002. 
CHIARADIA, F. A companhia de teatro São José: a menina-dos-olhos de Paschoal Segreto. 2012.

CORRÊA, M. Sobre a invenção da mulata. Cadernos Pagu. n. 6/ 7, p. 35-50. 1996.

DANTAS, C. V. O Brasil café com leite: debates intelectuais sobre mestiçagem e preconceito de cor na primeira república. Tempo. vol.13, n. 26, p. 56-79. 2009.

DAVIS, A. Mulheres, raça e classe. 2016.

DAVIS, Natalie Zenon. Culturas do povo: sociedade e cultura no início da França moderna. 1990.

FRANCA, L. P. Teatro amador: a cena carioca muito além dos arrabaldes. 2011. Dissertação (Mestrado em História) - Instituto de Ciências Humanas e Filosofia, Universidade Federal Fluminense.

GOMES, T. de M. Um Espelho no Palco. 2004.

GONDRA, J. G. \& Schueler, A. Educação, poder e sociedade no Império Brasileiro. 2008.

GUIMARÃES, A. S. A. Classes, Raças e Democracia. 2002.

HOOKS, B. Intelectuais negras. Estudos Feministas. n. 2, v. 3, 1995.

LANZARINI, J. As representações dos personagens "de cor" nas obras dramáticas de Artur Azevedo. In: Anais do XVI Encontro Regional de História da ANPUH-Rio: Saberes e práticas científicas. 2014.

LOPES, A. H. Vem cá, mulata! Tempo. v. 13, n. 26, p. 80-100. 2009.

MATTOS, H. Prefácio. In: Cooper, F, HOLT, T. C.\& SCOTT, R. J. Além da escravidão: Investigações sobre raça, trabalho e cidadania em sociedades pós-emancipação. 2005.

MATTOS, H. Raça e cidadania no crepúsculo da modernidade escravista. In: Grinberg, Keila; Salles, Ricardo. (orgs.) O Brasil imperial: 1870-1889. 2009. v.3.

MENDES, J. T. O Plano Agache: Propostas para uma Cidade-Jardim Desigual. Revista Habitus: revista eletrônica dos alunos de graduação em Ciências Sociais - IFCS/UFRJ. v. 10, n. 2, p. 116-127. dez. 2012.

MOURA, R. Tia Ciata e a pequena África do Rio de Janeiro. 2a ed. 1995.

MULLER, M. L. R. A produção de sentidos sobre mulheres negras e o branqueamento do magistério no Rio de Janeiro na Primeira República. Interfaces da Educ. v. 5, n. 14, p. 68-81. 2014. 
MUNANGA, K. Negros e Mestiços na obra de Nina Rodrigues. In: Almeida, A. \& Ferretti, L. (orgs). Religião, Raça e Identidade: colóquio do centenário da morte de Nina Rodrigues.

2009;

NUNES, M. 40 anos de teatro, v. 1. 1956.

ORTIZ, R. Cultura brasileira e identidade nacional. São Paulo: Brasiliense, 1986;

PEREIRA, A. A. O Mundo Negro: as relações raciais e a constituição do movimento negro contemporâneo no Brasil. 2013.

PEREIRA, L. A. de M. "Prazer das Morenas": bailes, ritmos e identidades nos clubes dançantes da primeira República. In: Marzano, A. \& Melo, V. (org.) Vida divertida: histórias do lazer no Rio de Janeiro (1830-1930). 2010;

REIS, Â. de C. Aprendizado atorial em âmbito familiar: paralelos entre o "teatro antigo" e o circo tradicional no Brasil. In: Anais do XXVIII Simpósio Nacional de História: Lugares de Historiadores: velhos e novos desafios. 2015.

. Cinira Polônio, a divette carioca: estudo da imagem pública e do trabalho de uma atriz no teatro brasileiro da virada do século XIX. 1999.

RUIZ, R. Araci Cortes: Linda Flor. 1984.

SÁ, C. M. de. Teatro Idealizado, Teatro Possível: uma estratégia educativa em Ouro Preto (1850-1860). 2009. 244f. Dissertação (Mestrado em Educação). Programa de Pós-Graduação em Educação.

SCHWARCZ, L. M. Nem preto nem branco, muito pelo contrário: cor e raça na sociabilidade brasileira. $1^{\text {a }}$ ed. 2012.

O Espetáculo das Raças. 1996;

SCOTT, J. W. Gênero: uma categoria útil para análise histórica. 1991.

SOUZA, J. G. R. da C. Corpos em Busca do Belo: as mulheres negras e a beleza na Era Vargas. In: Anais do Seminário Internacional Fazendo Gênero 11 \& 13th Women's Worlds Congress. 2017.

SOUZA, S. C. M. de. Do tablado às livrarias: edição e transmissão de textos teatrais no Rio de Janeiro da segunda metade do século XIX. In: Anais do IV Congresso Internacional de História. 2009.

SUSSEKIND, F. O Negro como Arlequim: Teatro e Discriminação Social. 1982.

TAVEIRA, L. de M. A Mulata e o Malandro: aspectos vocais do personagem-tipo na música do Teatro de Revista brasileiro, entre as décadas de 1880 e 1930. 2009. Dissertação (Mestrado em Música) - Universidade Federal do Estado do Rio de Janeiro. 
THOMPSON, E. P. A formação da classe operária inglesa: a força dos trabalhadores. 2. ed. 1989. Vol. III.

VASCONCELOS, M. C. C. A casa e seus mestres: a educação no Brasil do Oitocentos. 2005.

VELLOSO, M. P. Modernismo no Rio de Janeiro. Turunas e quixotes. 1996.

. Os cafés como espaço na moderna sociabilidade In: LOPES, Antônio Herculano (org.). Entre Europa e África: a invenção do carioca. 2000.

VENEZIANO, N. O teatro de revista no Brasil: dramaturgia e convenções. 1991.

XAVIER, G. A hora da estrela: Maria de Lourdes Vale Nascimento e as 'amigas leitoras' do jornal O Quilombo. In: Pinto, A. F. M \& Chalhoub, S.(orgs.). Pensadores negros Pensadoras negras: Brasil século XIX e XX. 2016.

Brancas de almas negras? Beleza, racialização e cosmética na imprensa negra pósemancipação (EUA, 1890-1930). 2012. 464f. Tese (Doutorado em História) - Instituto de Filosofia e Ciências Humanas, Universidade Estadual de Campinas.

Esculpindo a 'Nova Mulher Negra': feminilidade e respeitabilidade nos escritos de algumas representantes da raça nos EUA (1895-1904). Cadernos Pagu. n. 40, p. 255-287, jan./jun., 2013.

Segredos de penteadeira: conversas transnacionais sobre raça, beleza e cidadania na imprensa negra pós-abolição do Brasil e dos EUA. Estudos Históricos. vol. 26, n ${ }^{\text {52 }}$, p. 429 450. jul./dez. 2013.

\footnotetext{
${ }^{\mathrm{i}}$ Seguindo as orientações e Joan Scott, neste trabalho estamos articulando o conceito de gênero como um "elemento constitutivo de relações sociais fundadas sobre as diferenças percebidas entre os sexos". Para a autora, "o gênero é um primeiro modo de dar significado às relações de poder. [...] A política constrói o gênero, e o gênero constrói a política". (SCOTT, 1991)

ii Seguindo a concepção teórica sugerida pela historiadora Hebe Mattos, neste trabalho optamos por utilizar a designação negro em sentido contemporâneo, conforme o termo tem sido construído pelos movimentos negros no Brasil, como marca da escravidão e da origem africana e reivindicação identitária. Isso não significa que ignoramos o fato de que as designações de cor estiveram sujeitas às clivagens sociais, às desigualdades e às hierarquias da sociedade escravista, compreendendo que as várias designações de cor aludiam, historicamente, a conflitos e disputas. (MATTOS, 2009)

iii Carlos Espíndola, o pai de Aracy, nasceu em 1870 e morreu em 1920. Flautista, aprendeu a tocar com Antônio da Silva Salgado, professor da Escola de Música que morava próximo a sua residência. Como músico, Espíndola tornou-se figura constante em inúmeros bailes na Tijuca, Andaraí, Vila Isabel, Matoso e Itagipe, entre outras localidades do Rio de Janeiro, tocando choros, maxixes e lundus (RUIZ, 1984, p.18)

iv Alfredo da Rocha Viana Filho nasceu na cidade do Rio de Janeiro (RJ) em 23 de abril de 1897 e morreu, na mesma cidade, em 1973. Foi compositor, arranjador, flautista e saxofonista brasileiro. É considerado um dos mais importantes compositores da Música Popular Brasileira. Ver: CABRAL, Sérgio. Pixinguinha: vida e obra. Rio de Janeiro: FUNARTE, 2007.

${ }^{v}$ Atriz e cantora do teatro de revista, integrou a Companhia Negra de Revistas em 1926.

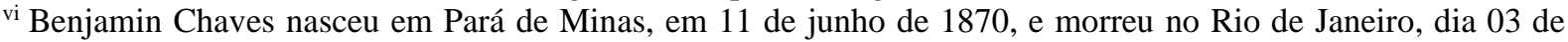
maio de 1954. Conhecido como Benjamin de Oliveira, foi um artista, compositor, cantor, ator e palhaço de circo brasileiro. Ele é mais conhecido por ser o primeiro palhaço negro do Brasil, além de ser o idealizador e criador do primeiro circo-teatro. O sobrenome "Oliveira" veio após se inspirar no nome de seu instrutor, Severino de Oliveira. Ver SILVA, Ermínia. Circo-teatro: Benjamim de Oliveira e a teatralidade circense no Brasil. São Paulo: Altana, 2007.
} 
vii Torna-se importante destacar que essa instituição se encontra em funcionamento até os nossos dias. Mesmo possuindo algumas interrupções ao longo de sua história, está aberta como Centro Cultural, nos convidando a conhecer uma importante parte da história teatral do nosso país.

viii Samba lançado na revista "Não Adianta Chorar". Ver: Não Adianta Chorar. Arquivos da 2a Delegacia Auxiliar de Polícia do Distrito Federal, Arquivo Nacional (2a DAP). Fundo 6E. Peças Teatrais, $\mathrm{n}^{\circ} 865$.

${ }^{\text {ix }}$ Miss Brasil. Arquivos da $2^{\mathrm{a}}$ Delegacia Auxiliar de Polícia do Distrito Federal, Arquivo Nacional (2a DAP). Fundo 6E. Peças Teatrais, $n^{\circ}$ 1442. p. 24.

${ }^{x}$ Para compreender melhor os meandros do universo cultural do Rio de Janeiro, e mais especificamente o teatro, emerge-se, metodologicamente e teoricamente, a necessidade de evidenciar o conceito de campo de Pierre Bourdieu. Para este, os campos caracterizam-se por espaços sociais, mais ou menos restritos, no qual as ações individuais e coletivas se dão dentro de uma normatização, criada e transformada constantemente por seus integrantes. Possuem, assim, suas próprias regras, princípios e hierarquias; sendo definidos a partir dos conflitos e das tensões que os permeiam (CHARTIER, 2002).

${ }^{x i}$ La Garçonne, Arquivos da $2^{\mathrm{a}}$ Delegacia Auxiliar de Polícia do Distrito Federal, Arquivo Nacional (2ª DAP). Fundo 6E. Peças Teatrais, $n^{\circ} 544$.

xii A eugenia foi um movimento que acreditava na perfectibilidade humana, a partir da genética, e que incentivou a "seleção da espécie", a partir do cruzamento entre indivíduos puros e superiores. A prática da eugenia teve seu ápice com a instituição do nazismo, na Alemanha governada por Adolf Hitler, a partir de 1933. Ver: CARULA, Karoline. Darwinismo, raça e gênero: Projetos modernizadores da nação em conferências e cursos públicos (Rio de Janeiro, 1870-1889). $1^{\text {a }}$ ed. Campinas: Editora UNICAMP, 2016.

xiii Francis Galton, nasceu em 16 de fevereiro de 1822, em Birmingham, na Inglaterra e morreu em 17 de janeiro de 1911 aos 88 anos de idade. Foi um antropólogo, meteorologista, matemático e estatístico inglês. Era primo de Charles Darwin e, baseado em sua obra, criou o conceito de "eugenia", que seria a melhora de uma determinada espécie, através da seleção artificial. O primeiro livro importante para o pensamento de Galton foi Hereditary Genius (1869).

${ }^{\text {xiv }}$ Representações em disputa sobre o teatro foram encontradas pela autora. Para alguns, era considerada arte supérflua, um artigo de luxo, especialmente aqueles que advogavam o investimento na atividade agrícola e nos ofícios fabris, que gerariam riquezas para a província. Outros alegavam que o teatro era prejudicial à formação moral dos jovens e das crianças da cidade e que apenas a escola seria local de sólida e idônea educação. Assim, percebendo o universo teatral como um intenso campo de disputas, Sá nos ajuda a compreender que o este era concebido de maneira diversa por cada grupo de indivíduos que se envolveu com encenações em Ouro Preto, durante o século XIX. (SÁ, 2010). 